\title{
„Sie werden nun ziemlich furchtsam sein“. Zukunftsangst in der mittelalterlich- isländischen Sagaliteratur
}

\begin{abstract}
Die Analyse von Emotionen ist im Bereich der skandinavistischmediävistischen Literaturwissenschaft eine vergleichsweise junge Erscheinung. Im vorliegenden Beitrag wird erstmals das Phänomen „Zukunftsangst“ in der umfangreichsten und bekanntesten der sogenannten Isländersagas, der Brennu-Njáls saga („Die Saga vom verbrannten Njáll“), auf der Figurenebene näher beleuchtet und eine erste Bestandsaufnahme vorgelegt.

Analysing emotions is still a relatively recent approach in the field of Old Norse literary studies: In this article, I am examining anxiety about the future in medieval Icelandic Brennu-Njáls saga ("Njal's saga”; “The story of burnt Njal”). Instead of focussing on the impact of fate and dreams on the plot, I am approaching the topic by analysing dialogues and the characters' behaviour on the intradiegetic level.
\end{abstract}

\section{Emotionen und „Zukunft“ in der altisländischen Literatur}

Während sich diverse Geisteswissenschaften schon seit vielen Jahren mit Fragen der historischen Emotionsforschung befassen, ${ }^{1}$ ist die Auseinandersetzung mit dem Thema „Emotionen“ im Bereich der skandinavistisch-mediävistischen Literaturwissenschaft eine verhältnismäßig junge Erscheinung. ${ }^{2}$ Im Folgenden wird erstmals das Phänomen „Zukunftsangst“ in der umfangreichsten und be-

1 Vgl. Gerok-Reiter \& Obermair (2007: 3).

2 Zwar wurden Emotionen insbesondere in der altisländischen Sagaliteratur durchaus erkannt und von der Forschung angesprochen. Allerdings nutzte die ältere Forschung „Emotionen“ hauptsächlich im Rahmen einer psychologisierenden Figurenanalyse. Erst Sif Ríkharðsdóttir (2017) hat die in den Texten geschilderten Gefühlsäußerungen unter Zuhilfenahme moderner literaturwissenschaftlicher Fragestellungen untersucht.

Anmerkung: Brennu-Njáls saga, c. 69, 171: ,[M]unu peir nú vera hófliga hræddir.' Alle Übersetzungen aus dem Altisländischen sind meine eigenen. 
kanntesten der sogenannten Isländersagas, der Brennu-Njáls saga („Die Saga vom verbrannten Njáll“), näher beleuchtet.

In ihrer Einleitung zur Festschrift für Gerhard Wolf, die den Titel Krise und Zukunft in Mittelalter und (Früher) Neuzeit. Studien zu einem transkulturellen Phänomen trägt, vertreten die Germanisten Susanne Knaeble und Silvan Wagner die Ansicht, dass sich der Terminus „Zukunft“ nicht als erwartbares Ereignis, sondern im modernen Sinne als offener Zukunftshorizont verstanden weder im Mittelhochdeutschen, noch im Frühneuhochdeutschen eindeutig nachweisen lasse. ${ }^{3}$ Das Phänomen Zukunft begegne hingegen in Formen der Vorhersage, Planung und Prognose auch in den kulturellen Zeugnissen der Vormoderne. Auf dem Kontinent sind dies etwa Chroniken mit prognostischer Qualität der Beschäftigung mit der Vergangenheit und Gegenwart: Ziel ihrer Darstellung sei nicht allein die Archivierung von Wissen, sondern der Versuch, aus den beobachteten Strukturen Prognosen für die Zukunft, und vielleicht sogar konkrete Handlungsanweisungen zu finden.

Die altisländische Sagaliteratur wartet mit einer beträchtlichen Zahl an Adjektiven und Substantiven auf, die die Fähigkeit, in die Zukunft sehen zu können, zum Ausdruck bringen: So bezeichnet etwa das feminine Substantiv framsýn die Vorausschau, Zukunftsschau, oder auch die Sehergabe; framvísi, ebenfalls ein Femininum, bedeutet „Wissen um die Zukunft“ sowie „Sehergabe“, während die forspá mit Prophezeiung, Voraussage und Voraussicht übersetzt werden kann. Die zugehörigen Adjektive sind framsýnn (,vorausschauend“, ,,in die Zukunft blickend“), framvíss (,zukunftskundig“) und forspár („,zukunftskundig“).

Das Phänomen Zukunft ist in der altnordischen Literatur untrennbar mit dem Terminus Schicksal verknüpft, das, wie es scheint, keinen offenen $\mathrm{Zu}$ kunftshorizont darstellt, sondern unumstößlich an erwartbare Ereignisse geknüpft ist. Insbesondere in der Eddadichtung ist das unausweichliche und unveränderliche Schicksal der Götter und Menschen präsent: In der sogenannten „Weissagung der Seherin“ (an. Völuspá), prophezeit eine Seherin dem Gott Óðinn die sogenannten Ragnarǫk („Schicksal der Götter“), das Ende der Welt, und somit den Untergang der Götter, das in Gestalt der drei Nornen, die als Symbole des Schicksals präsentiert werden, offenbart wird. Das über den Göttern stehende Schicksal findet sich auch in den Vafprúðnismál („Reden des Vafprúðnir“), in denen sich der Gott Óðinn in einem Wissenswettstreit mit dem weisen Riesen Vafprúðnir misst. In Strophe 39 begegnet der Ausdruck aldar rök

3 Vgl. Knaeble \& Wagner (2017: 9). 
(,Endschicksal der Welt“). ${ }^{4}$ Eine übergeordnete Rolle spielt das (tragische) Schicksal auch in den eddischen Heldenliedern sowie in den sogenannten „Heldensagas“, eine Untergruppe der Vorzeitsagas, die Stoffe der Heldendichtung verarbeiten. Insbesondere der Gott Óðinn übernimmt in diesen Texten die Rolle des Schicksalsbringers, wie zum Beispiel in der Helgakviða Hundingsbana II (,Das zweite Lied von Helgi, dem Töter Hundings“) oder der Vọlsunga saga.

Für die altnordischen Königssagas (konungasögur) ist die sogenannte hamingja, auch mit „Königsglück“ übersetzt, lange Zeit von der Forschung im Zusammenhang mit dem Schicksalsglauben gedeutet worden, dem die Protagonisten unterworfen seien. Dieser Ansicht ist erst in jüngster Zeit im Zusammenhang mit der Kontingenzforschung widersprochen worden. ${ }^{5}$ Während sich in der Vergangenheit in Bezug auf die altnordische Dichtung sowie die Vorzeitsagas und die Königssagas diverse Arbeiten mit den Themen Schicksal und Prophezeiung beziehungsweise Weissagung auseinandergesetzt haben, ist die diesbezügliche Forschungsliteratur für die Isländersagas von weit geringerem Umfang.

Allerdings haben sich zwei jüngst erschienene Aufsätze mit dem „Schicksal“ und damit verbundenen dem Phänomen Zukunft auseinandergesetzt: In ihrem Beitrag zum 2017 erschienenen Routledge Research Companion to the Medieval Icelandic Sagas konzentriert sich Stefanie Gropper auf die Analyse des Schicksals in den Isländersagas - in den Texten vornehmlich als gæfa, gipta oder hamingja bezeichnet. Sie kommt zu dem Schluss, dass in den Isländersagas zunächst kein Widerspruch zwischen dem Schicksal und dem freien Willen bestehe. Stattdessen gebe es eine zwingende Verbindung zwischen Schicksal und Ehre - was das Schicksal verlange, müsse demnach das Anliegen eines jeden Mannes werden, wenn er in Ehre leben oder sterben wolle. ${ }^{6}$ Dieser ideale Parallelismus kann gelegentlich von gravierenden Ereignissen durchbrochen werden, wie zum Beispiel, wenn das Schicksal den Mord an einem Verwandten (er-)fordert. In solchen Momenten wird Schicksal als Verhängnis (böses Schicksal) angesehen, dem nicht entronnen werden kann. Dennoch stellt das Schicksal eine Aufgabe und eine Gelegenheit zur Selbstverwirklichung dar, das keinerlei Gesetzen der Natur oder einer Verbindung von Ursache und Wirkung folgt. Der Mensch kann folglich zwar seinem Schicksal nicht entrinnen, aber er hat die Wahl, das Beste daraus zu machen, d. h. das Schicksal bietet die Möglichkeit, ein Held zu werden.

\footnotetext{
4 Vgl. z.B. Simek (2004: 8-10).

5 Vgl. van Nahl (2017: 328-330).

6 Vgl. Gropper (2017: 199).
} 
Kristýna Králová identifizierte kürzlich unterschiedliche Modelle von Vorahnungen in den unterschiedlichen Sagagenres: ${ }^{7}$ So seien Strukturunterschiede hinsichtlich Form, Inhalt, Zeitumfang und geographischem Bereich der vorausgeahnten Ereignisse zu verzeichnen. Das bedeutet beispielsweise, dass Vorahnungen an einen bestimmten Ort (auf Island), an ein ganzes Land oder gar die ganze Welt gebunden sein können. Letzteres trifft etwa auf die sogenannten Vorzeitsagas (formaldarsögur) zu. Allen Sagagenres gemeinsam ist dagegen, dass ausschließlich das Schicksal der aktuell handelnden Figuren im Text „prognostiziert“ wird, nicht jedoch das ihrer Kinder und nachfolgender Generationen.

Vorahnungen nehmen zudem viele unterschiedliche Formen an: Es handelt sich dabei nicht nur um Träume, die aber zweifelsohne zu den häufigen Formen zählten. Der schwedische Literaturhistoriker Peter Hallberg zählte im Schnitt drei bis vier Träume pro Isländersaga. ${ }^{8}$ Daneben kommen durchaus Prophezeiungen, Omen, Ahnungen oder einfache Warnungen vor, die Figuren im Gespräch äußern. Die Inhalte von Vorahnungen seien nicht stereotyp, sondern können stark voneinander abweichen: so gebe es negative, positive, im übertragenen Sinn oder wörtlich zu verstehende Vorausdeutungen. Allerdings bleibt festzuhalten, dass die meisten solcher Ahnungen negativer Natur sind - das gilt auch für die Isländersagas: Träume etwa, die Kämpfe, Waffen und viel Blut beinhalten prophezeien meist den Tod der träumenden Figur - der Träumende erfährt aufgrund der dargestellten Ereignisse oft negative Gefühle, wie Schmerz, Ärger oder Angst. Die Gísla saga Súrssonar, („Die Geschichte von Gísli Súrsson“) hält besonders prägnante und blutige Traumepisoden bereit, die sich häufen, je näher das Ende des Protagonisten und damit das Ende der Erzählung, rückt. ${ }^{9}$

\section{Angst in den Isländersagas}

Obwohl das Mittelalter geprägt war von diversen Ängsten, wie etwa der Angst vor Krankheiten, Hungersnöten, Kriegen sowie der Sünde, ${ }^{10}$ scheint die mittelalterliche Literatur der pathologischen Angst wenig Aufmerksamkeit zu schenken: So konstatierte Annette Gerok-Reiter 2007 für die mittelhochdeutsche Heldenepik, dass es bezüglich der Untersuchung von „Angst“ in den Texten gleich

\footnotetext{
7 Vgl. Králová (2017: 24-50).

8 Vgl. Hallberg (1969: 73).

9 Vgl. Králová (2017: 24-50).

10 Vgl. allgemein Dinzelbacher (1996: 9-23).
} 
zu mehreren Problemen komme, die sie als „Handicaps“ bezeichnete: So komme Angst, im Sinne pathologischer Angst, schlicht und ergreifend in der deutschen Heldenepik nicht vor. ${ }^{11}$ Darüber hinaus sei „[d]as Phänomen der Angst [...] appliziert auf den Protagonisten, so unwürdig, dass es noch nicht einmal in den Katalog der wiedergutzumachenden Fehler aufgenommen werden kann. “" Zudem gelte für die Protagonisten der mittelalterlichen Literatur, dass sie bereits von Geburt an überaus mutig seien und dies auch ihr ganzes Leben hindurch blieben. Das Thema des ängstlichen Protagonisten habe dagegen keinerlei literarische Dignität. ${ }^{13}$

Als drittes Handicap bezeichnet Gerok-Reiter die Figurenzeichnung, da die Figurendarstellung in der Regel keine Introspektiven, keine Subjektivität kenne. Aber wie gelingt es, Angstdarstellungen in Texten $\mathrm{zu}$ untersuchen, in denen narrative Normen vorliegen, die trotz oder gerade wegen der angsterfüllten Realität das Thema „Angst“ radikal zurückdrängen? Annette Gerok-Reiter demonstriert am Beispiel des Rolandslieds, wie sich Figuren verhalten, die ganz offensichtlich von Angst erfüllt sind. Körperhaltung, Kleidung, Gesichtsfarbe, aber auch verbale Äußerungen der Figuren bringen „Inneres durch Äußeres“ zum Ausdruck und kehren ihre Emotionen dadurch für den Rezipienten wahrnehmbar nach außen.

Ähnlich verhält es sich in den Isländersagas: In den meisten Texten werden Protagonisten mitnichten als ängstlich beschrieben. Sie sind mutig und bringen sich, zu Tode verwundet, noch ein letztes Mal mit markigen Sprüchen ins Gedächtnis des Rezipienten, bevor sie schließlich tot zusammenbrechen. ${ }^{14}$ Die Protagonisten fürchten nicht einmal gefährliche übernatürliche Erscheinungen und Ereignisse, wie etwa Wiedergänger, durch böse Zauberei hervorgebrachte Wetter- und Klimaphänomene, oder Flüche. Als ängstlich (hræddr; fælinn) ${ }^{15}$ werden in vielen Fällen dagegen Figuren von niedrigerem gesellschaftlichen Status, wie etwa Sklaven, beschrieben. Sie überkommt regelmäßig panische Angst, die sie zu Handlungen veranlasst, die ihren Tod bedeuten. Ausnahmen von dieser Regel finden sich allerdings in den auch als „Geächtetensagas“ bezeichneten Isländersagas: Zwar behalten auch in diesen Texten die Sklaven ihre

11 Vgl. Gerok-Reiter (2007: 128-130).

12 Gerok-Reiter (2007: 129).

13 Vgl. Gerok-Reiter (2007: 129); vgl. außerdem zu Angst in mittelhochdeutschen Erzähltexten Gerok-Reiter (2010a); Gerok-Reiter (2010b); vgl. ferner Filatkina (2016).

14 Torfi Tulinius hat vor einigen Jahren das dramatische und vermeintlich furchtlose Ableben der Figuren mit Sigmund Freuds umstrittenem Ansatz des Todestriebs zu erklären versucht. Vgl. Tulinius (2015: 99-115).

15 Vgl. Sif Ríkharðsdóttir (2017:37). 
Furchtsamkeit, die Protagonisten haben aber ebenfalls explizit Angst: In der Gísla saga Súrssonar („Die Geschichte von Gísli Súrsson“) wird der Protagonist mit zunehmender Intensität seiner Albträume als myrkhræddr bezeichnet, und die Grettis saga Ásmundarsonar („Die Geschichte von Grettir Ásmundarson“) nennt ihren Titelhelden myrkfælinn - beide Adjektive bringen Angst vor der Dunkelheit zum Ausdruck. ${ }^{16}$ Diese Angst vor der Dunkelheit spielt im Handlungsverlauf beider Sagas eine nicht unerhebliche Rolle. ${ }^{17}$

\subsection{Die Brennu-Njáls saga. Damals und heute}

Im Februar 1912 berichtet ein gewisser Hermann Jónasson im Rahmen eines Vortrags in Reykjavík von einer unerhörten Begebenheit: In einer Nacht um den Jahreswechsel 1892/93 habe er einen ungewöhnlichen Besucher gehabt: Ein gut aussehender, ca. fünfzigjähriger Mann mit dunklem Haar und Vollbart habe ihn in seinem Schlafzimmer aufgesucht und sich zunächst erkundigt, ob Hermann vollständig wach sei. Er sei gekommen, um seinem Gastgeber, der sich in der Öffentlichkeit bereits einen Namen als Seher gemacht hatte, die Wahrheit über die altisländische Brennu-Njáls saga („Die Saga vom verbrannten Njáll“) und die in ihr geschilderten Begebenheiten zu erzählen, da er wisse, dass Hermann brennendes Interesse für die Saga hege. In seinen Ausführungen berichtigt der nächtliche Besucher einige Handlungsabschnitte bezüglich ihres historischen Gehalts und gibt Auskunft zur Entstehung der Saga und ihrer Überlieferung. Schließlich stellt sich heraus, dass es sich bei Hermanns Gast um Ketill Sigfússon í Mǫrk, einen Schwiegersohn des Sagaprotagonisten Njáll Porgeirsson, handelt. Ketill fordert Hermann auf, seinen Bericht genau aufzuschreiben und zu verbreiten, damit jeder die Wahrheit über die Brennu-Njáls saga erfahre. ${ }^{18}$

So ungeeignet diese Traumerscheinung des Hermann Jónasson für die wissenschaftliche Arbeit eines Sagaforschers zunächst erscheinen mag, so sehr belegt sie das ungebrochene Interesse der Isländer an ihrer mittelalterlichen Literatur, insbesondere an der als künstlerisch herausragend geltenden BrennuNjáls saga, oftmals Njáls saga oder schlicht Njála genannt: Noch heute kennt

16 Gísla saga Súrssonar, c. 33, 104; Grettis saga Ásmundarsonar, c. 51, 163.

17 Erwähnenswert ist in Bezug auf Lichtverhältnisse der Unterschied zwischen dem Kontinent und der nordatlantischen Insel, weshalb hier nicht die Angst vor der Nacht angesprochen wird: Während in Mitteleuropa Dunkelheit und Nacht in unmittelbarem Zusammenhang stehen, so gelten für den Norden durchaus andere Regeln: Schließlich sind isländische Sommernächte überwiegend hell, während im Winter selbst tagsüber völlige Dunkelheit herrschen kann.

18 Vgl. Hermann Jónasson (1912: 40-97). 
jeder Isländer die Geschichte um den weisen und zukunftssichtigen Protagonisten Njáll Porgeirsson, der schließlich - im Zuge mehrerer schwerwiegender Fehden - mitsamt seiner Familie Opfer eines Mordbrands (altisländisch brenna) wird.

Islands Literaturnobelpreisträger Halldór Kilján Laxness befasste sich 1945, im ersten Jahr der isländischen Unabhängigkeit, in seinem Aufsatz Minnisgreinar um fornsögur („Anmerkungen zu den Sagas“) intensiv mit der Njáls saga und hob in erster Linie ihren Status als literarisches Kunstwerk hervor. ${ }^{19}$ Das Arnamagnäanische Institut in Reykjavík widmet sich seit 2012 einem Forschungsprojekt zur Varianz in den bisher bekannten über 70 Handschriften der um 1280 entstandenen Saga. ${ }^{20}$ Der Germanist Alois Wolf bezeichnete sie kürzlich gar als „Islandepos“21. Aber nicht nur Literaturschaffende und Mediävisten hegen Interesse an der Erzählung, sie hat längst Eingang in die isländische Alltagskultur gefunden, wie u. a. die Comicbuchreihe Sögur úr Njálu (,Geschichten aus der Njála“), das Museumsprojekt Njálurefill („Njáls saga-Teppich“) oder das 2016 am Reykjavíker Stadttheater inszenierte Drama Njála belegen. ${ }^{22}$

\subsection{Zur Forschungsgeschichte}

Der Analyse dieser umfangreichsten aller Isländersagas haben sich bis zum heutigen Tag zahlreiche Einzelstudien gewidmet, die von der Untersuchung der handschriftlichen Überlieferung, über die Erzählstruktur bis hin zur Interpretation einzelner Figuren und der sie umgebenden mittelalterlichen Umwelt inklusive der Anwendung altisländischen Rechts reichen. Ein besonderer Fokus lag dabei stets auf den Einflüssen kontinentaler Literatur und christlicher Theologie. Sowohl die Handlung als auch einzelne Protagonisten sind häufig im Lichte der Christianisierung Islands interpretiert worden. Insbesondere die Figur des Njáll wurde nicht selten als Märtyrer gelesen, der trotz seiner „guten“ Ratschläge zur friedlichen Konfliktbeilegung am Ende den üblen Machenschaften seiner Feinde zum Opfer fällt.

19 Vgl. Jón Karl Helgason (2005: 65); Halldór Kiljan Laxness (1945: 55-56).

20 Zum Projekt Breytileiki Njáls sögu. Variance of Njáls saga vgl. die Projekthomepage: https://www.arnastofnun.is/is/breytileiki-njals-sogu (10.07.2019).

21 Wolf (2014: 99).

22 Vgl. Embla Ýr Bárudóttir \& Ingólfur Örn Björgvinsson (2003-2007); zum Njáls saga-Teppich vgl. die Projekthomepage https://www.njalurefill.is/ (10.07.2019); Sauckel (2017); zur Inszenierung am Borgarleikhús vgl. Davíð Kjartan Gestsson (2016). 
In jüngster Zeit wurde dieser gängigen Deutung der Saga als Erzählung von Islands Bekehrung und einem damit verbundenen Wertewandel - von heidnischer „Rachekultur“ zu christlicher Nächstenliebe - innerhalb der präsentierten Gesellschaft allerdings widersprochen: So fällen beispielsweise die Sagaforscher Theodore Andersson, William Ian Miller und Daniel Sävborg in ihren Lesungen der Saga bezüglich des Protagonisten ein kritischeres Urteil:.23 Ihren Interpretationen gemeinsam ist die Erkenntnis, dass es sich bei Njáll nicht um einen aufopferungsvollen Märtyrer handle, der seinen Tod in den Flammen selbst gewählt habe. Vielmehr habe Njáll aus Berechnung gehandelt, beziehungsweise am Ende zu hoch gepokert, weshalb er schließlich Opfer des Mordbrands geworden sei. Zudem könne die von der Forschung vertretene These bezüglich eines radikalen Wertewandels, der sich ab dem Zeitpunkt der geschilderten Christianisierung manifestiere, nicht aufrechterhalten werden; schließlich geschehen weiterhin brutale Rachemorde und auch der Hebride Kári Solmundarson, Njálls Schwiegersohn und einziger Überlebender des grausamen Mordbrands an Njáll und seiner Familie, strebt nicht nach einer friedlichen Kompensation. Erst nachdem er seine Verwandten durch 15 Totschläge gerächt hat, willigt er in einen Vergleich ein. Darüber hinaus wartet die Erzählung mit einer Reihe invertierter sagatypischer sozialer Normen und Erzählmuster auf, die einen Subtext erzeugen, in dem gültige Normen eher infrage gestellt als zementiert werden. ${ }^{24}$

Weiteres Augenmerk richtete die Forschung auf die ungewöhnliche Erzählstruktur der Njáls saga: So zerfällt die Erzählung um den Titelhelden deutlich in zwei große Abschnitte; ihnen voran geht eine längere Episode um einen Verwandten Gunnarr Hámundarsons; mit letzterem verbindet den Protagonisten eine tiefe Freundschaft. Nach dem Tod Njálls in den Flammen verzweigt sich die Handlung weiter in Episoden um den Rächer Kári Solmundarson, der nach seinem Rachefeldzug im Ausland schließlich wieder nach Island zurückkehrt und sich dort mit Flosi Pórðarson, dem Initiator des Mordbrands, aussöhnt. Diese episodenhafte, auch als lose kompiliert bezeichnete Struktur der Saga sowie die Diskussion um ihre inhaltliche Einheit hat die Forschung lange Zeit vor Rätsel gestellt. So hat man u. a. angenommen, dass die Njáls saga eine Kompilation aus mindestens zwei Sagas sei.

In der deutschsprachigen Forschung ist die Njáls saga innerhalb der letzten drei Jahrzehnte nur selten Gegenstand umfangreicher Einzelstudien gewesen: Mit der oben zitierten Monographie des Germanisten Alois Wolf „Die Saga von

23 Vgl. Andersson (2006); Miller (2014); Sävborg (2014: 251-257); Tirosh (2014: 208-226).

24 Vgl. Andersson (2006: 183-203); Sauckel (2016: 94-115); Sauckel (2018: 223-237). 
der Njálsbrenna und die Frage nach dem Epos im europäischen Mittelalter“ wurde sie zuletzt im Zusammenhang mit der deutschsprachigen Epik betrachtet; Ziel von Wolfs Analyse war u. a. das Bewusstsein der deutschsprachigen Germanistik für die altnordische Sagaliteratur zu wecken.

\subsection{Zukunft und Zukunftsangst in der Brennu-Njáls saga}

Die Njáls saga stellt in Bezug auf diverse Forschungsthemen der Sagaforschung eine Ausnahme dar - so auch im Hinblick auf das den Sagas inhärente Schicksal: Aufgrund der Hinwendung zum Christentum durch die Protagonisten wird das Schicksal besonders im letzten Drittel der Handlung nicht mehr als alleiniger Weg gezeichnet; an dessen Stelle tritt allmählich die Providenz. ${ }^{25}$ Ich möchte mich im Folgenden jedoch nicht auf die übergeordnete Frage der Präsenz von Schicksal und Providenz konzentrieren, da dies bereits an anderer Stelle erfolgt ist. ${ }^{26}$ Vielmehr soll schlaglichtartig auf der Figurenebene untersucht werden, inwiefern der Protagonist Njáll Porgeirsson, der in der Vergangenheit als aufopferungsvoller Märtyrer interpretiert wurde, von seiner Sehergabe Gebrauch macht, um sich und seinen Angehörigen Vorteile zu schaffen, inwiefern er dadurch Zukunftsängste schürt und um welche Art von Ängsten es sich dabei handelt.

Bereits vor Einführung des Protagonisten in die Sagahandlung, wird von negativen Vorahnungen der Figuren und damit verbundenen Ängsten berichtet: In Kapitel 3 bricht Hrútr Herjólfsson mit seinem Onkel Qzurr nach Norwegen auf, um das Erbe seines getöteten Bruders Eyvindr für sich zu beanspruchen. In Vik angekommen überbringt ihnen ein Diener der Königinmutter Gunnhildr eine private Botschaft; seine Herrin bietet den beiden Isländern Unterkunft für den Winter und ihre Freundschaft an. Nach einem Gespräch unter vier Augen, dessen Inhalt dem Sagarezipienten verborgen bleibt, wendet sich Qzurr an Hrútr:

,Svá lízk mér, frændi, sem nú muni vit hafa gọt ráo okkat, bví at ek kann skapi Gunnhildar: jafnskjótt sem vit viljum eigi fara til hennar, mun hon reka okkr ór landi, en taka fé okkat allt með ráni; en ef vit fọrum til hennar, pá mun hon gera okkr slíka sœmð sem hon hefir heitit.'

25 Vgl. Gropper (2017: 201).

26 Vgl. Winterbourne (2004: 98-100; 136); Bek-Pedersen (2009: 29); Hamer (2014); Lönnroth (1976: 123-136). 
['Es sieht mir so aus, Verwandter, als ob wir nun unseren Beschluss bereits gefasst hätten, denn ich kenne Gunnhildrs Art: Sobald wir nicht zu ihr gehen wollen, wird sie uns aus dem Land jagen, und all unser Vermögen mit Gewalt an sich nehmen; aber wenn wir uns zu ihr begeben, wird sie uns solche Ehre erweisen, wie sie sie uns versprochen hat.' $]^{27}$

Hrútr und Qzurr bleibt zu diesem Zeitpunkt nichts anderes übrig als nach dem Willen der Königin zu handeln und in ihren Gemächern den Winter zu verbringen. Es handelt sich in diesem Beispiel um die Angst vor konkretem Status- und Ehrverlust. Diese Angst wiegt so schwer, dass sich Hrútr im weiteren Handlungsverlauf der Königinmutter als Liebhaber zur Verfügung stellt. Auf diese Weise gelingt es ihm auch, das mittlerweile von Seeräubern gestohlene Vermögen seines Bruders zurückzuholen, da Gunnhildr ihn militärisch unterstützt.

Der Titelheld der Saga, der erst in Kapitel 21 der Íslenzk Fornrit-Edition in die Handlung eingeführt wird, wird als zukunftskundig charakterisiert:

Njáll bjó at Bergpórshváli [...]; annat bú átti hann í Pórólfsfelli. Hann var vel auðigr at fé ok vænn at áliti, en sá hlutr var á ráði hans at honum óx eigi skegg. Hann var logmaðr svá mikill, at engi fannsk hans jafningi, vitr var hann ok forspár, heilráðr ok góðgjarn, ok varð allt at ráði, pat er hann réð mǫnnum, hógværr ok drenglýndr, langsýnn ok langminnigr; hann leysti hvers manns vandræði, er á hans fund kom.

[Njáll wohnte auf Bergbórshváll [...]; einen anderen Hof hatte er in Pórólfsfell. Er war vermögend und von schönem Äußeren, aber dieses Merkmal hatte er an sich, dass ihm kein Bart wuchs. Er war ein so hervorragender Gesetzeskenner, dass ihm keiner gleichkam, weise war er und zukunftskundig, er erteilte gute Ratschläge und war friedliebend, und alles, was er den Leuten riet, bewährte sich; er war umgänglich und edelmütig, sah weit voraus und konnte sich lange zurückerinnern. Er löste die Probleme eines jeden, der zu ihm kam. $]^{28}$

Aufgrund dieser eingehenden Charakterisierung der Figur muss es bemerkenswert erscheinen, dass Njáll in den Arbeiten, die sich Weissagern und Sehern in der altnordischen Literatur gewidmet haben, wie etwa Simone Horsts 2010 erschienene Monografie „Merlin und die völva. Weissagungen im Altnordischen“229, die ein Kapitel über „zukunftskundige Figuren“ enthält, nicht erwähnt wird. Auch Jón Hnefill Aðalsteinssons Artikel zu Wahr- und Weissagen im Reallexikon der Germanischen Altertumskunde zählt diverse Sagafiguren auf, spart Njáll jedoch aus. ${ }^{30}$

27 Brennu-Njáls saga, c. 3, 12-13.

28 Brennu-Njáls saga, c. 20, 57.

29 Vgl. Horst (2010).

30 Vgl. Jón Hnefill Aðalsteinsson (2006: 81-85). 


\subsubsection{Njálls „guter“ Rat}

Njáll erteilt anderen Figuren, wie etwa Familienmitgliedern und Freunden, juristische Ratschläge, die er nicht selten mit einer Zukunftsprognose in Bezug auf einen möglichen Erfolg oder Misserfolg ihres Anliegens versieht. Neben seinen Söhnen ist der häufigste Empfänger dieser Beratungen Njálls treuer Freund Gunnarr Hámundarson, der als vermögender Landbesitzer und stattlicher Krieger in die Handlung eingeführt wird. ${ }^{31}$ Im Zuge einer schwerwiegenden Fehde mit seinem Erzfeind Mǫðr Valgarðsson ersucht Gunnarr Njáll in Kapitel 55 nicht nur um Rat, sondern bittet ihn ganz konkret um einen Blick in die Zukunft:

„Hversu mun nú ganga síðan?‘ segir Gunnarr. ,Villt bú, at ek segja pér pat,‘ segir Njáll, ,er eigi er fram komit? Pú munt ríða til pings, ok muntú njóta við ráða minna ok fá af pessu ina mestu sœmð. Mun petta upphaf vígaferla pinna. 'Ráð pú mér heilræði nǫkkur,' segir Gunnarr. ,Ek skal bat gera,' segir Njáll; ,veg pú aldri meir í inn sama knérunn en um sinn ok rjúf aldri sætt pá, er góðir menn gera meðal bín ok annarra, ok pó sízt á pví máli.“

[,Wie wird es nun weitergehen?‘ sagt Gunnarr. ,Willst du, dass ich dir sage,‘ sagt Njáll, ,was noch nicht geschehen ist? Du wirst zum Thing reiten und von meinem Rat profitieren und davon die größte Ehre davontragen. Das wird für dich der Anfang einer Reihe von Totschlägen sein. ',Gib mir nun einen guten Rat,' sagt Gunnarr. ,Das werde ich tun, 'sagt Njáll; , begehe niemals einen zweiten Totschlag in derselben Geschlechtslinie und brich niemals einen Vergleich, den gute Männer zwischen dir und anderen gestiftet haben, am allerwenigsten in dieser Sache.' $]^{32}$

Anhand der Tatsache, dass Gunnarr seinen Freund Njáll zuerst um einen Blick in die Zukunft bittet, und nicht um eine konkrete Handlungsanweisung oder einen taktischen Kniff, lässt sich erkennen, dass der tatkräftige Sagaheld nicht nur ratlos ist, sondern Angst vor bevorstehenden Konsequenzen hat. Njálls Zukunftsschau verstärkt diese Angst, da sie in Bezug auf eventuelle Totschläge in derselben Familie und dem Brechen eines Vergleichs eine eindringliche Warnung bereithält. Sie wird im weiteren Gesprächsverlauf sogar noch verschärft: Denn sollte sich beides - ein wiederholter Totschlag in derselben Familie sowie der Bruch eines bereits geschlossenen Vergleichs - gleichzeitig ereignen, ,pá munt pú skammt eiga ólifat, en ella munt pú verða gamall maðr.' [,Dann wirst du nur noch kurze Zeit zu leben haben, aber andernfalls wirst du ein alter Mann werden.' $]^{33}$ Dank der Ratschläge seines Freundes wird Gunnarr in der Fehde

31 Vgl. Brennu-Njáls saga, c. 19, 52-53.

32 Brennu-Njáls saga, c. 55, 139.

33 Brennu-Njáls saga, c. 55, 139. 
zunächst die Oberhand behalten und - wie Njáll es bereits vorhergesehen hat die „größte Ehre davontragen“.

Bemerkenswert an der Beratschlagung der beiden Männer ist aber auch, dass sich Gunnarr umgekehrt für Njálls Zukunft interessiert und ihn dazu befragt:

Gunnarr mælti: ,Veizt pú, hvat pér mun verða at bana?‘,Veit ek,‘ segir Njáll. ,Hvat?‘ segir Gunnarr. ,Pat, sem allir munu sízt ætla,' segir Njáll. Síðan reið Gunnarr heim. [Gunnar sprach: ,Weißt du, was dir den Tod bringen wird?‘ ,Das weiß ich,' sagt Njáll. ,Was?’ sagt Gunnarr. ,Das, was alle am wenigsten erwarten,‘ sagt Njáll. Dann ritt Gunnarr nach Hause. $]^{34}$

Auf Gunnarrs Angst vor der nahen, bedrohlich wirkenden, aber dennoch ungewissen Zukunft, folgt Njálls Gewissheit in Bezug auf seinen eigenen Tod. Die ausführlich gestaltete Beratungsszene dient an dieser Stelle der Handlung jedoch nicht nur dazu, das Innenleben der Figuren zum Ausdruck zu bringen; sie stellt vielmehr ein spannungssteigerndes Element dar, das durch die Ausgestaltung mit direkter Rede dem Rezipienten im Gedächtnis bleibt. ${ }^{35}$

Als es im Zuge von Gunnarrs Fehde zum zweitem Mal zu einer bewaffneten Auseinandersetzung mit Toten kommt, unterstützt Njáll seinen Freund abermals mit juristischer Versiertheit: Um eine Anklage auf dem Thing gegen Gunnarr abzuwenden, beziehungsweise, um einen Vergleich der beiden Parteien erzwingen zu können, tritt Njáll zwei eigene Rechtsangelegenheiten an ihn ab. Zudem rät er Gunnarr so schnell wie möglich die von ihm im Kampf getöteten Männer an der Kampfstätte auszugraben, sich Zeugen zu ernennen und die Toten für friedlos zu erklären, da sie ihn mit der Absicht, ihn zu ermorden, angegriffen hätten. Außerdem rät er seinem Freund, einen weiteren Verbündeten aufzusuchen, der ihm eine Totschlagsklage abtreten könne. Letzterer habe die Klage wegen Erschlagung seines Bruders zu führen. Als die Gegner schließlich ihre Klage gegen Gunnarr vorbereiten, solle Gunnarr einen der erschlagenen Widersacher des Mordes an seinem Bruder Hjortr anklagen. ${ }^{36}$ Njálls Übertragung von Klagen an seinen Freund und die genaue Instruktion bei der Ernennung von Zeugen sind nicht die einzigen Mittel, mit denen er Gunnarr unter die Arme greift.

Während der Verhandlung stellt sich Njáll schützend vor seinen Freund und steht der Gegenpartei Rede und Antwort: So erkundigt sich Mǫrðr Val-

34 Brennu-Njáls saga, c. 55, 139.

35 Vgl. Lönnroth (1989: 83).

36 Vgl. Brennu-Njáls saga, c. 64-65, 160-163. 
garðsson nach Gunnarrs Rechtsfähigkeit, die ihm der weise Ratgeber kurzerhand erläutert. Dieser sei durchaus rechtsfähig, da Njáll persönlich ihn auf einer Thingversammlung im vorangegangenen Herbst für rechtsfähig erklärt habe. ${ }^{37}$ Ebenso entkräftet er das Argument Mǫrðrs, der Tote Gegner könne gar nicht für die Erschlagung von Gunnarrs Bruder Hjǫrtr angeklagt werden, und zwar schlicht und ergreifend, weil Gunnarr ihn unter Zeugen zum Totschläger erklärt habe. ${ }^{38}$ Schließlich wundert sich der Initiator des Angriffs, weshalb Gunnarr die Angreifer für friedlos gefallen erklärt habe. Njáll entgegnet, sie seien mit der Absicht, Körperverletzung und Totschlag $\mathrm{zu}$ begehen, aufgebrochen. Auch wenn Gunnarr nicht verletzt worden sei, so habe einer seiner Brüder den Angriff mit seinem Leben bezahlen müssen, der andere mit einer schweren Verletzung. Dem auf diese Weise Belehrten bleibt nichts weiter übrig als festzustellen: ,Log hafið pér at mæla,' segir Morðr, ,pó at hart sé undir at búa.' ['Das Gesetz habt ihr auf eurer Seite,' sagt Mǫðr, 'doch es ist hart, sich dem beugen zu müssen.'] $]^{39}$

Die Aussage des Antagonisten Mǫrðr Valgarðsson ist eine der wenigen innerhalb der Saga, die die Gefühlslage von Njálls und Gunnarrs Gegnern zum Ausdruck bringen: Die Feststellung, dass es schwierig sei, sich Njálls Versiertheit beugen zu müssen, bedeutet nämlich auch, sich der rechtlichen und politischen Vormachtstellung von Njáll und seinem Freund Gunnarr unterordnen, beziehungsweise unterwerfen zu müssen. Folglich verwundert es nicht, dass die bereits zum wiederholten Mal gescheiterten und in ihrer Ehre erniedrigten Feinde Gunnarrs nach weiteren Vergeltungsschlägen trachten, wozu sie die recte Angst vor weiterem Ehrverlust und finanziellen Einbußen anstacheln wird. Im weiteren Handlungsverlauf gelingt es dem Antagonisten, Gunnarr mittels ehrenrühriger Provokation in eine Falle zu locken, die sein von Njáll vorhergesehenes negatives Schicksal besiegeln wird. Gunnarr wird schließlich auf seinem eigenen Hof im Kampf erschlagen. Njáll unterstützt daraufhin Gunnarrs Sohn Hogni bei der Vaterrache, indem er mit seinem Sohn Skarpheðinn, ein gefürchteter und äußerst schlagkräftiger Krieger, einen - wohlgemerkt nächtlichen - Vergeltungsangriff plant. Nachdem es den beiden jungen Männern bereits gelungen ist, mehrere der Mörder niederzustrecken, machen sie sich auf den Weg zum Hof des eigentlichen Initiators an dem Angriff auf Gunnarr:

37 Vgl. Brennu-Njáls saga, c. 66, 165.

38 Brennu-Njáls saga, c. 66, 165: ,Rett var pat,' segir Njáll, ,par sem hann kaus hann til vegenda með váttum'. ['Das war rechtens,' sagt Njáll, 'da er ihn vor Zeugen zum Totschläger ernannt hat.']

39 Brennu-Njáls saga, c. 66, 165. 
Paðan fara peir [Skarpheðinn ok Họgni] til Hofs, ok var Mǫrðr úti á velli ok bað sér griða ok bauð alsætti. [Dann ziehen sie [Skarpheðinn ok Họgni] nach Hof, und Mǫrðr war [bereits] draußen auf der Hauswiese und bat um Pardon und bot vollen Vergleich an. ${ }^{40}$

In dieser Szene tritt die Angst vor dem eigenen Tod in Mọrðrs Verhalten deutlich hervor: Im Gegensatz zu seinen Verbündeten, die sich zum Zeitpunkt des Rachezugs noch weitgehend nichtsahnend in ihren Häusern aufhalten, erwartet der Antagonist einen Angriff. Weil er der Kampfkraft Skarpheðinns nichts entgegenzusetzen hat, läuft er den Angreifern unbewaffnet und ohne Schutz auf freier Fläche entgegen und signalisiert noch bevor er schließlich um Schonung bittet, seine Bereitschaft zur Unterwerfung und bekräftigt sie mit einem Vergleichsangebot. Diese Schilderung der Angst vor einem gewaltsamen Tod ist für eine Figur wie Mǫðr Valgarðsson durchaus ungewöhnlich: der Sohn eines Goden, also eines Bezirkshäuptlings, lässt sich in den Isländersagas für gewöhnlich nicht zu einer solchen Unterwerfungsgeste hinreißen. Um Gnade und Schonung zu flehen ist eher typisch für Sklaven oder andere (Neben-)figuren von niedrigem sozialen Status. Die Szene um Morðrs Angst dient allerdings nicht dazu, die körperliche Unterlegenheit des Antagonisten gegenüber Skarpheðinn zum Ausdruck zu bringen: Der Sohn Njálls handelt auf diesem Rachezug als Exekutive seines Vaters. Vielmehr ist es Njáll, dem Mơrðr unterlegen ist, wie in den nachfolgenden Episoden deutlich wird, die von den Vergleichsverhandlungen berichten: Die Verhandlungen auf dem Thing enden damit, dass Mǫrðr die komplette Vergleichssumme allein (!) entrichten muss.

\subsubsection{Njálls Zukunftsangst}

Doch auch der Seher Njáll selbst ist nicht vor ausgeklügelten Plänen seiner Gegner gefeit - wie Kapitel 110 eindrucksvoll beweist: Es handelt sich um jene Szene, in der der bereits zuvor erwähnte Antagonist und Intrigant Mǫrðr Valgarðsson die Njálssöhne zum Mord an ihrem von Njáll über alles geliebten Ziehbruder, Hǫskuldr Práinsson, aufhetzt. Inhaltliche Details der Unterhaltung von Mǫrrr und den Njálssöhnen werden allerdings nicht geschildert:

Bergpóra spurði Njál: „Hvat tala peir úti?‘ „Ekki em ek í ráðagerð með peim,‘ segir Njáll; ,sjáldan var ek pá frá kvaddr, er in góðu váru ráðin.

40 Brennu-Njáls saga, c. 79, 195. 
[Bergpóra fragte Njáll: 'Was reden die da draußen?' 'Ich bin an ihrer Beratung nicht beteiligt,' sagt Njáll; 'selten war ich ausgeschlossen, wenn die Ratschläge guter Natur waren'. $]^{41}$

Diese Unterhaltung zwischen Mǫror und den Njálssöhnen auf Bergpórshváll ist übrigens das einzige Mal in der Saga, dass sich Njáll zwar in unmittelbarer Nähe einer (geheimen) Beratschlagung seiner Söhne befindet, aber nicht Teil von ihr ist. In der Feststellung des Protagonisten, dass er selten abwesend gewesen sei, wenn seine Söhne „gute Ratschläge“ ersonnen hätten, verbirgt sich eine negative Vorahnung gemischt mit Zukunftsangst um die sich anschließend ereignenden Begebenheiten.

Nach der Tötung des Ziehsohns durch seine leiblichen Söhne ist Njáll von Trauer, aber auch von seiner Angst vor den Konsequenzen tief bewegt:

,Hǫrmulig tíðendi,‘ segir Njáll, ,ok er slíkt illt at vita, pví at pat er sannligt at segja, at svá fellr mér nær um trega, at mér pœtti betra at hafa látit tvá sonu mína ok væri Hǫskuldr á lífi.‘ ,Pat er nú nǫkkur várkunn, ‘ segir Skarpheðinn; ,pú ert maðr gamall, ok er ván, at pér falli nær.‘ ,Eigi er bat síðr,' segir Njáll, ,en elli, at ek veit gørr en pér, hvat eptir mun koma. ‘ „Hvat mun eptir koma?‘ segir Skarpheðinn. ,Dauði minn,‘ segir Njáll, ,ok konu minnar ok allra sona minna.

['Das sind beklagenswerte Neuigkeiten,' sagt Njáll, 'und so etwas ist schlimm zu erfahren, weil es wahr ist, dass es mir so nahe geht, dass ich es lieber gehabt hätte, wenn ich zwei meiner Söhne verloren hätte und Họsuldr noch am Leben wäre.' 'Das ist nun begreiflich,' sagt Skarpheðinn; 'du bist ein alter Mann und es ist zu erwarten, dass es dir nahegeht.' 'Die Ursache meines Kummers ist nicht nur mein Alter,' sagt Njáll, 'sondern ebenso sehr, dass ich besser weiß als du, was darauf folgen wird.' 'Was wird darauf folgen?' sagt Skarpheðinn. 'Mein Tod,' sagt Njáll, ‘und der meiner Frau und aller meiner Söhne.'] ${ }^{42}$

Wie diese Szene eindrücklich zum Ausdruck bringt, nimmt die Angst des Protagonisten vor seinem eigenen Tod mit Fortschreiten der Handlung zu: In dieser Auseinandersetzung mit seinem ältesten Sohn Skarpheðinn steht die Angst vor dem eigenen Ende an dritter und somit wichtigster Stelle: Zunächst äußert Njáll, dass der Mord an seinem Ziehsohn ihm nahegehe, dann erfährt seine Trauer eine Steigerung, indem der verzweifelt anmerkt, dass er für Hǫskuldrs Leben zwei seiner leiblichen Söhne geopfert hätte; schließlich erfolgt die Vorahnung und Prophezeiung, dass dieses Ereignis die Auslöschung seiner Familie zur Folge haben wird.

Njáll widerspricht in dieser Szene zum ersten Mal vehement seinem ältesten Sohn Skarpheðinn: Bis zu diesem Punkt herrscht meist Übereinstimmung in-

41 Brennu-Njáls saga, c. 110, 280.

42 Brennu-Njáls saga, c. 111, 282. 
nerhalb einer Konversation. Mit der Ermordung seines Ziehsohnes Họskuldr zerreißt das Band zwischen Vater und Sohn, was durch den heftigen Widerspruch und der Prophezeiung zum Ausdruck gebracht wird.

Im weiteren Verlauf der Handlung spitzt sich die angespannte Lage zwischen den mittlerweile diversen Konfliktparteien aufgrund der Ermordung Hǫskuldrs weiter zu, bis der entscheidende Vergleich zwischen Njálls Familie und den Angehörigen des Ermordeten scheitert. An eine friedliche Einigung ist nicht mehr zu denken und Njálls Vorahnungen bezüglich seines Todes nehmen deutlich Gestalt an: Während Njálls Ehefrau in Kapitel 127 für ihre Hausleute Essen auftragen lässt und sie in dunkler Vorahnung bittet, sich ihre Lieblingsspeise auszusuchen, hat ihr Mann eine Erscheinung:

,Undarliga sýnisk mér nú. Ek pykkjumsk sjá um alla stufuna, ok pykki mér sem undan sé gaflveggirnir báðir, en blóðugt allt borðit ok matrinn.

['Ich habe eine merkwürdige Erscheinung: Es kommt mir so vor, als sähe ich die ganze Stube, aber mir scheint, als seien die beiden Giebelwände verschwunden, und der ganze Tisch und das Essen voller Blut.'] ${ }^{43}$

Weiter wird erzählt, dass alle Anwesenden Njálls Erscheinung große Bedeutung beimessen. Schließlich erfolgt der bekannte Angriff auf Njálls Hof Bergpórshváll, in dessen Verlauf der Mordbrand verübt wird, der so gut wie sämtliche Bewohner auslöscht: Als die Angreifer heranziehen, bittet Njáll seine Männer um eine Einschätzung der Gegner. Skarpheðinn bezeichnet sie zwar als starke Mannschaft, die jedoch nicht unüberwindbar sei, solange sich die Verteidiger stets vor dem Haus aufhielten. ${ }^{44}$ Kurioserweise widerspricht Njáll seinem ältesten Sohn, einem erfahrenen Krieger, abermals vehement und befiehlt allen, ins Haus zu gehen. Schließlich hätten es die Angreifer auch schwer gegen Gunnarr gehabt, als er sich in seinem Haus verteidigt habe. Skarpheðinn kann die Strategie seines Vaters nicht gutheißen:

,Petta er ekki bann veg at skilja, ‘ [...] ,Gunnar sóttu heim peir hǫfðingjar, er svá váru vel at sér, at heldr vildu frá hverfa en brenna hann inni. En pessir munu sœkja oss með eldi, ef peir megu eigi annan veg, pví at peir munu allt til, at yfir taki við oss. Munu peir pat ætla, sem eigi er ólíkligt, at pat muni beira bani, ef oss dregr undan. Em ek ok ófúss pess at láta svæla mik inni sem melrakka í greni.‘

['Das ist nicht auf diese Weise zu verstehen,' [...] 'Gunnarr wurde von denjenigen Häuptlingen aufgesucht, die so rechtschaffen waren, dass sie eher abziehen wollten, als ihn drinnen zu verbrennen. Aber die hier werden uns mit Feuer angreifen, wenn sie keine an-

43 Brennu-Njáls saga, c. 127, 324.

44 Brennu-Njáls saga, c. 128, 326. 
dere Lösung finden, weil sie alles daran setzen würden, um mit uns fertigzuwerden. Sie werden [das] denken, was nicht unwahrscheinlich ist, dass es ihr Tod wäre, wenn wir entkommen. Ich bin auch nicht begierig darauf, mich drinnen ausräuchern zu lassen wie ein Fuchs im Bau.'] ${ }^{45}$

Bemerkenswert an Skarpheðinns Antwort ist die Ausführlichkeit, mit der er der Erklärung seines Vater und dem Befehl, sich ins Haus zurückzuziehen, entgegentritt. Aus vermeintlichem Trotz und Unwillen, als Krieger im Kampf eine Niederlage zu erleiden, lässt sich die Angst vor dem Tod herauslesen. Sehr treffend verwendet er an dieser Stelle die Metapher des Fuchses im Bau für seinen Vater..$^{46}$

\subsection{Angst und Zukunft in der Brennu-Njáls saga}

Was Annette Gerok-Reiter für die Angstdarstellungen in der mittelhochdeutschen Epik formuliert hat, gilt im Kern auch für die Schilderungen von Angstzuständen, einschließlich der Zukunftsangst, in den Isländersagas; Ausnahmen finden sich v.a. in den Sagas um geächtete Protagonisten, wie der eingangs erwähnten Gísla saga und der Grettis saga. Trotz ihrer Ängste sterben diese Figuren einen heldenhaften Tod und bleiben dem Rezipienten als Helden in Erinnerung. Mein Beitrag ist ein erster Versuch, die Phänomene „Angst“ und „Zukunft“ in der Brennu-Njáls saga zu untersuchen - losgelöst von der bereits bestehenden Forschung zum Terminus „Schicksal“ - und eine erste Bestandsaufnahme vorzulegen.

Die Figuren dieser Saga entsprechen an der Oberfläche den in den Isländersagas präsentierten sozialen Normen; insbesondere die Aufrechterhaltung der (männlichen) Ehre spielt in der Saga eine übergeordnete Rolle, wie im Zusammenhang mit der Analyse des Phänomens Angst zum Ausdruck kommt. Auch scheint eine Verbindung zu bestehen zwischen der Intensität der Angst und der Länge einzelner Aussagen der Protagonisten: So erkundigt sich Gunnarr zunächst nach dem weiteren Verlauf der Ereignisse, bittet um Rat und fragt sein Gegenüber nach dem Tod. In Gunnarrs ausführlicher, gesteigerter Anfrage liegt die Angst vor dem eigenen Tod, aber auch vor konkretem Ehrverlust. Große Angst vor dem Verlust von Ehre und Ansehen hat auch der Antagonist Mǫrðr

45 Brennu-Njáls saga, c. 128, 326.

46 Wie kaum ein anderer Protagonist der Isländersagas wendet Njáll sein Wissen um die Zukunft, sein juristisches Können und durchaus fragwürdige Listen an, um seine Ziele zu erreichen. 
Valgarðsson. Zwar sind in den entsprechenden Szenen seine Aussagen und Gesten nicht so ausführlich wie die von Gunnarr, doch sind sie prägnanter gestaltet - wie etwa die Feststellung, dass es hart sei, dass das Gesetz auf Seiten der Gegner sei, oder auch die ritualisierte Unterwerfungsgeste, während des Angriffs durch Skarpheðinn und Họgni. Diese Ängste werden durch das Taktieren Njálls und seine dadurch erreichten Erfolge geschürt, was schließlich dazu führt, dass sein Freund Gunnarr getötet wird. Njálls eigene Angst vor der Zukunft wird markiert durch die Frage nach dem Vorhaben seiner Söhne, die sich in Kapitel 79 ohne ihren Vater beraten. Seine konkrete Furcht vor dem Tod kommt schließlich in Kapitel 111, als sein Sohn ihm die Ermordung Hǫskuldrs mitteilt, verstärkt zum Ausdruck und erfährt eine weitere Steigerung in der Vision seines in Blut getränkten Hauses. Schließlich äußert sich Skarpheðinn zur Verteidigungstaktik seines Vaters und widerspricht ihr nachdrücklich: Die ausführliche Erläuterung zur Kriegstaktik sowie seine Verwendung der Metapher vom Fuchs im Bau veranschaulichen seine Angst vor einem drohenden Feuertod, die durch seinen Willen zum Kampf relativiert wird.

Wie die ausgewählten Beispiele gezeigt haben, sind die Zukunftsängste der Figuren in der Njáls saga konkreter Natur - Kontingenzangst lässt sich dagegen nicht belegen. Diese Ängste äußern sich je nach Figurentypus unterschiedlich: Die tapferen Protagonisten bringen meist in ausführlicher direkter Rede sowie in Form von Fragen nach der Zukunft oder (taktischen) Vorahnungen ihre Angst zum Ausdruck. Beispiele hierfür wären etwa die Beratschlagung von Gunnarr und Njáll im Zuge von Gunnarrs Fehde sowie das Gespräch zwischen Njáll und seinem Sohn Skarpheðinn nach der Ermordung Hǫskuldrs.

Um die Angst des Antagonisten Mọrðr Valgarðsson zu verdeutlichen, werden dagegen unterschiedliche Gestaltungsmittel verwendet: Hier sind es entweder kürzere, prägnante Aussagen, die Resignation oder Verzweiflung erkennen lassen oder die eindeutige Unterwerfungsgeste, die anzeigen sollen, dass der Antagonist nicht die geforderten Normen der altisländischen Sagagesellschaft erfüllt. Es gilt nun, diese anfängliche Bestandsaufnahme zum Thema „Zukunftsangst“ in weiteren Schritten zu vertiefen und die narrativen Systematiken dieses „Epos der Isländer“ stärker herauszuarbeiten.

\section{Literatur}

Jón Hnefill Aðalsteinsson (2006): Wahrsagen und Weissagen. In: Heinrich Beck et al. (Hrsg.), Reallexikon der Germanischen Altertumskunde 233 , 81-85. Berlin/New York: De Gruyter. Andersson, Theodore M. (2006): The Growth of the Medieval Icelandic Sagas (1180-1280). Ithaca, London: Cornell University Press. 
Embla Ýr Bárudóttir \& Ingólfur Örn Björgvinsson (2003-2007): Sögur úr Njálu. Reykjavík: Mál og menning.

Bek-Pedersen, Karen (2009): Fate and Weaving: Justification of a Metaphor. Viking and Medieval Scandinavia 5, 23-39.

Breytileiki Njáls sögu. Variance of Njáls saga: https://www.arnastofnun.is/is/breytileiki-njalssogu (10.07.2019).

Dinzelbacher, Peter (1996): Angst im Mittelalter. Teufels-, Todes-, und Gotteserfahrung: Mentalitätsgeschichte und Ikonographie. Paderborn u. a.: Ferdinand Schöningh.

Filatkina, Natalia (2016): Darumb kam eine seer grosse furcht vnd schrecken in das Volck. angest vs. vorhte - Martin Luther als Wendepunkt? In: Nina Bartsch \& Simone SchultzBalluft (Hrsg.), PerspektivWechsel oder Wiederentdeckung der Philologie. Band 2: Grenzgänge und Grenzüberschreitungen. Zusammenspiele von Sprache und Literatur in Mittelalter und Früher Neuzeit. Festschrift für Klaus-Peter Wegera, 67-89. Berlin: Erich Schmidt.

Gerok-Reiter, Annette (2007): Die Angst des Helden und die Angst des Hörers. Stationen einer Umbewertung in mittelhochdeutscher Epik. Das Mittelalter: Perspektiven mediävistischer Forschung 12, 127-143.

Gerok-Reiter, Annette \& Sabine Obermair (2007b): Angst und Schrecken als kulturelle Matrix. Einleitung. Das Mittelalter: Perspektiven mediävistischer Forschung 12, 3-6.

Gerok-Reiter, Annette (2010a): angest/vorhte - literarisch. Möglichkeiten und Grenzen der Emotionsforschung zwischen Text und Kontext. In: Daniela Hammer-Tugendhat \& Christina Lutter (Hrsg.), Emotionen. Zeitschrift für Kulturwissenschaften, herausgegeben von Thomas Hauschild und Lutz Musner, 15-22.

Gerok-Reiter, Annette (2010b): Angst - Macht - Ohnmacht. Emotionscrossing in Hartmanns Erec? In: Ingrid Kasten (Hrsg.), Machtvolle Gefühle (Trends in Medieval Philology 24), 218245. Berlin, New York: De Gruyter.

Davíð Kjartan Gestsson (2016): Njála er „einstakur viðburður“. https://www.ruv.is/frett/njalaer-einstakur-vidburdur (10.07.2019).

Gísla saga Súrssonar. In: Björn K. Pórólfsson \& Guðni Jónnson (Hrsg.) (1943): Vestfirðinga sogur (Íslenzk Fornrit VI), 1-118. Reykjavík: Hið íslenzka fornritafélag.

Grettis saga Ásmundarsonar. In: Guðni Jónsson (Hrsg.) (1936): Grettis saga Ásmundarsonar. Bandamanna saga. Odds páttr Ófeigssonar (İslenzk Fornrit VII), 1-290. Reykjavík: Hið íslenzka fornritafélag.

Gropper, Stefanie (2017): Fate. In: Ármann Jakobsson \& Sverrir Jakobsson (Hrsg.), The Routledge Research Companion to The Medieval Icelandic Sagas, 198-209. New York: Routledge.

Hallberg, Peter (1969): Den isländska sagan. Andra upplagan (Verdandis skriftserie 6). Stockholm: Svenska bokförlaget.

Hamer, Andrew (2014): Njáls saga and its Christian Background: A Study of Narrative Method (Mediaevalia Groningana New Series 20), Leuven u. a.: Peeters.

Jón Karl Helgason (2005): Continuity? The Icelandic Sagas in Post-Medieval Times. In: Rory McTurk (Hrsg.), A Companion to Old Norse-Icelandic Literature and Culture, 64-81. Malden/MA u. a.: Blackwell.

Horst, Simone (2010): Merlin und die völva. Weissagungen im Altnordischen (Münchner Nordistische Studien 5). München: Herbert Utz.

Hermann Jónasson (1912): Draumar. Erindi flutt i Reykjavík í Febrúar 1912. Reykjavík: Ísafoldprentsmiðja. 
Knaeble, Susanne \& Silvan Wagner (2017): Vorwort und Einleitung. In: Nadine Hufnagel, Susanne Knaeble, Silvan Wagner \& Viola Wittmann (Hrsg.), Krise und Zukunft in Mittelalter und (Früher) Neuzeit. Studien zu einem transkulturellen Phänomen, 7-16. Stuttgart: S. Hirzel.

Králová, Kristýna (2017): What did the Future hold for them? Different Types of Foreshadowing in Various Saga Genres. European Journal of Scandinavian Studies 47 (1), 24-50.

Halldór Kiljan Laxness (1945): Minnisgreinar um fornsögur. Tímarit Máls og menningar, 13-56. Lönnroth, Lars (1976): Njáls saga: A Critical Introduction. Berkeley u. a.: Berkeley University Press.

Lönnroth, Lars (1989): Rhetorical Persuasion in the Sagas. In: John Tucker (Hrsg.), Sagas of the Icelanders. A Book of Essays (Garland Reference Library of the Humanities 758), 71-98. New York/London: Garland.

Miller, William I. (2014): 'Why is your axe bloody?' A reading of Njáls saga. Oxford: Oxford University Press.

Nahl, Jan Alexander van (2017): Krise und Kontingenz. Zu einem literaturwissenschaftlichen Potenzial am Beispiel Islands. In: Andrea Bartl \& Marta Famula (Hrsg.), Vom Eigenwert der Literatur. Reflexionen zu Funktion und Relevanz literarischer Texte (Konnex. Studien im Schnittbereich von Literatur, Kultur und Natur 21), 311-332. Würzburg: Königshausen \& Neumann.

Sif Ríkharðsdóttir (2017): Emotion in Old Norse Literature. Translation, Voices, Contexts (Studies in Old Norse literature 1). Woodbridge: Boydell \& Brewer.

Sauckel, Anita (2016): Brennu-Njáls saga: An Old Icelandic trickster (discourse)? In: Daniela Hahn \& Andreas Schmidt (Hrsg.), Bad Boys and Wicked Women. Antagonists and Troublemakers in Old Norse Literature (Münchner Nordistische Studien 27), 94-115. München: Herbert Utz.

Sauckel, Anita (2017): Fogr er hli̊ðin ... („Schön ist der Hang ...“). Das „Njál’s saga Centre“ in Hvolsvöllur (Sögusetrið Hvolsvelli)“. Mittelalter - Interdisziplinäre Forschung und Rezeptionsgeschichte. http://mittelalter.hypotheses.org/11244 (10.10.2017).

Sauckel, Anita (2018): Brennu-Njáll als scheiternder Trickster oder: Warum ein Seidengewand keinen Vergleich bricht. In: Alessia Bauer \& Alexandra Pesch (Hrsg.), Hvanndalir. Beiträge zur europäischen Altertumskunde und mediävistischen Literaturwissenschaft (Ergänzungsbände zum Reallexikon der Germanischen Altertumskunde 106), 223-237. Berlin/Boston: De Gruyter.

Sävborg, Daniel (2014): Konfliktlösning og religion i Njáls saga. Slutreplik till Lars Lönnroth. Gripla 25, 251-257.

Simek, Rudolf (2004): Schicksalsglaube. In: Heinrich Beck et al. (Hrsg.), Reallexikon der Germanischen Altertumskunde 27, 8-10. Berlin/New York: De Gruyter.

Einar Ól. Sveinsson (Hrsg.) (1954): Brennu-Njáls saga (İslenzk Fornrit XII). Reykjavík: Hið íslenzka fornritafélag.

Tirosh, Yoav (2014): Víga-Njáll. A new approach toward Njáls saga. Scandinavian Studies 86 (2), 208-226.

Torfi H. Tulinius (2015): Seeking Death in Njáls saga. In: Jeffrey Turco (Hrsg.), New Norse Studies: Essays on the Literature and Culture of Medieval Scandinavia (Islandica 58), 99-115. Ithaca: Cornell University Press.

Winterbourne, Anthony (2004): When the Norns Have Spoken: Time and Fate in Germanic Paganism. Madison: Fairleigh Dickinson University Press.

Wolf, Alois (2014): Die Saga von der Njálsbrenna und die Frage nach dem Epos im europäischen Mittelalter (Beiträge zur nordischen Philologie 53). Tübingen: Francke. 